\title{
Into the origin and diversification of Podolian cattle breeds by testing Neolithic scenarios of European colonization using genome-wide SNP data
}

Gabriele Senczuk ${ }^{1}$, Salvatore MASTRANGELO ${ }^{2}$, Paolo Ajmone Marsan ${ }^{3}$, Zsolt Becskei ${ }^{4}$, Paolo Colangelo ${ }^{5}$, Licia Colli ${ }^{3}$, Luca Ferretti ${ }^{6}$, Taki Karsli ${ }^{7}$, Hovirag Lancioni ${ }^{8}$, Emiliano Lasagna $^{9}$, Donata Marletta ${ }^{10}$, Christian Persichilli ${ }^{1}$, Baldassare PORTOLANO ${ }^{2}$, Francesca Sarti $^{9}$, Elena Ciani ${ }^{11}$, and Fabio Pilla ${ }^{1}$

${ }^{1}$ Università degli Studi del Molise

${ }^{2}$ Università degli Studi di Palermo

${ }^{3}$ Università Cattolica del Sacro Cuore Sede di Piacenza e Cremona Facoltà di Agraria

${ }^{4}$ University of Belgrade

${ }^{5} \mathrm{CNR}$

${ }^{6}$ Università degli Studi di Pavia

${ }^{7}$ Akdeniz University

${ }^{8}$ Universita degli Studi di Perugia

${ }^{9}$ Università degli Studi di Perugia

${ }^{10}$ Università degli Studi di Catania Facoltà di Agraria

${ }^{11}$ Università degli Studi di Bari Aldo Moro

October 18, 2020

\begin{abstract}
Together with the Neolithic human expansions, cattle spread from domestication centres and colonized the world. During their tangled expansion dynamics, European cattle occasionally intermingled with local aurochs leading to an exclusive pattern of genetic diversity. Among the most ancient European cattle, are breeds belonging to the so-called Podolian trunk which their history is still not well established. Here we used genome-wide SNP data of 806 individuals belonging to 36 breeds to reconstruct the origin and diversification of the Podolian cattle and to provide a reliable scenario of the European colonization, through an Approximate Bayesian Computation approach. Our results indicate that European Podolian cattle displays higher values of all genetic diversity indices when compared to both African taurine and Asian indicine. All our clustering analyses show close genomic relationships among Podolian breeds suggesting their possible common genetic ancestry. When we simulated and tested scenarios of colonization, we found that Podolian cattle followed different colonization routes, in line with two principal human migrations: via the Danube during the early stages of the Neolithic farmer expansions and through sea routes likely during the pre-Etruscan period. Furthermore, the best fitting model indicates that these two genomic pools admixed in Italy suggesting the Peninsula as an important hub for the Podolian cattle.
\end{abstract}

\section{Hosted file}

Main text_submis-2.pdf available at https://authorea.com/users/368118/articles/487380-intothe-origin-and-diversification-of-podolian-cattle-breeds-by-testing-neolithic-scenariosof-european-colonization-using-genome-wide-snp-data 

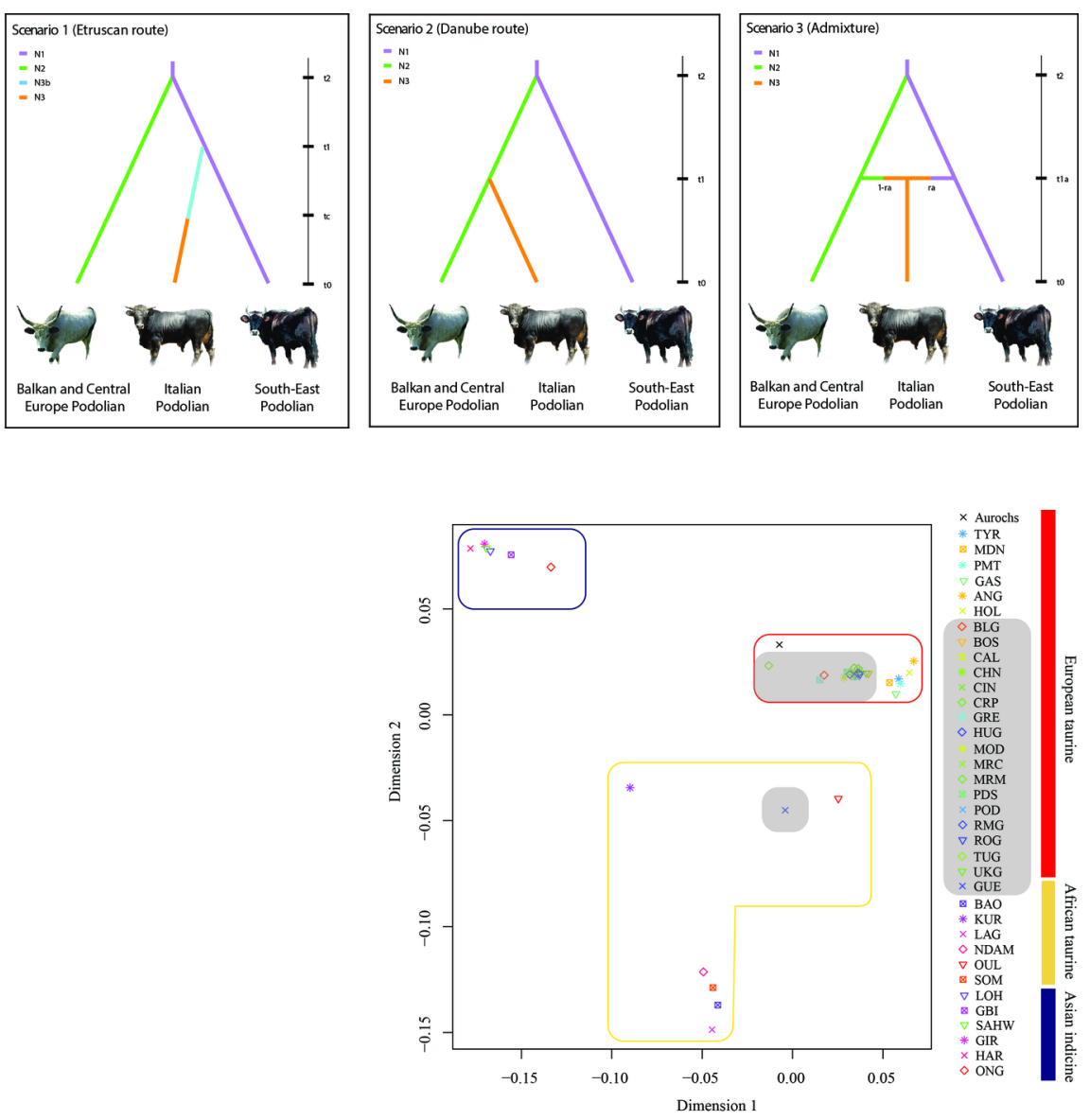


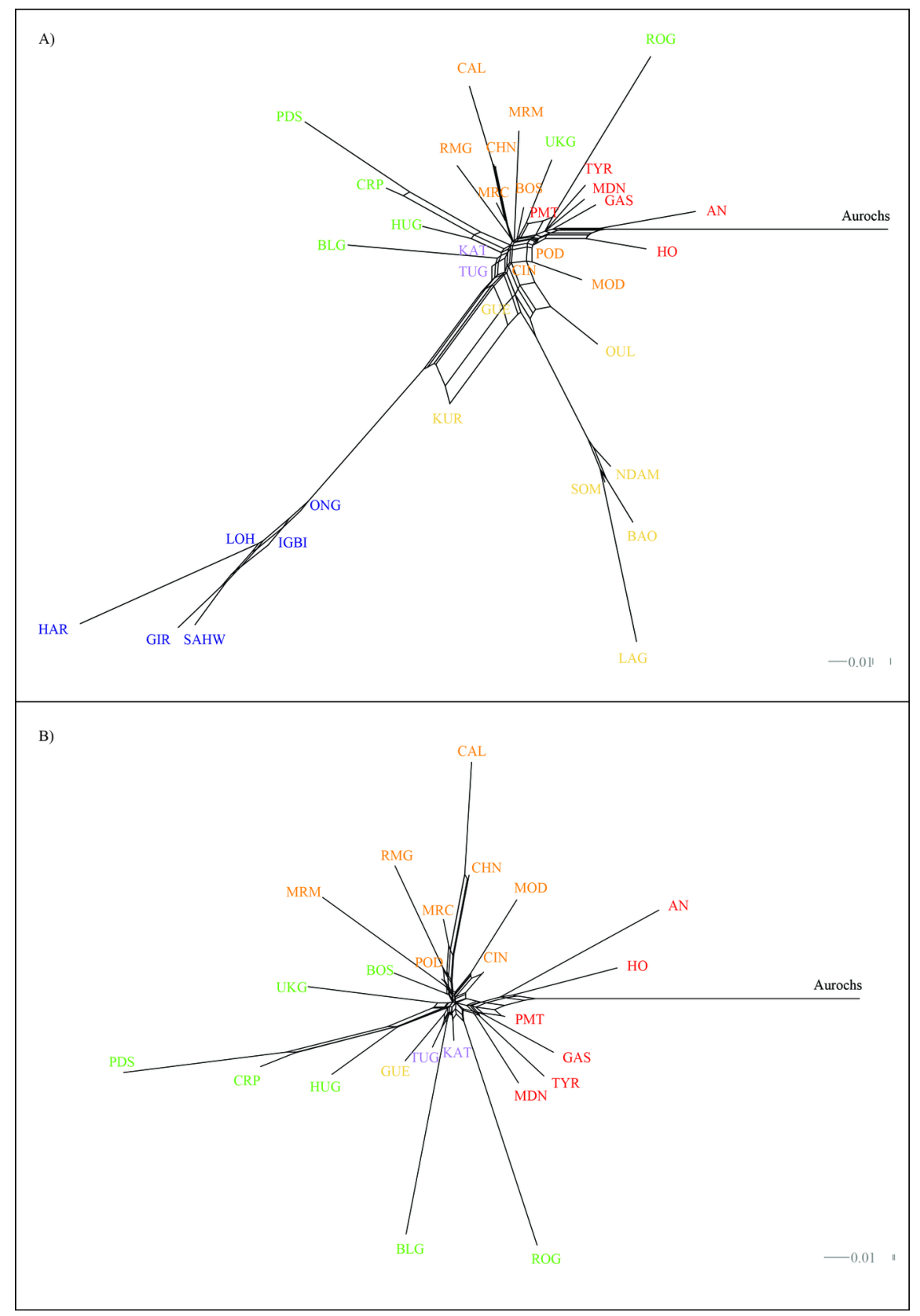




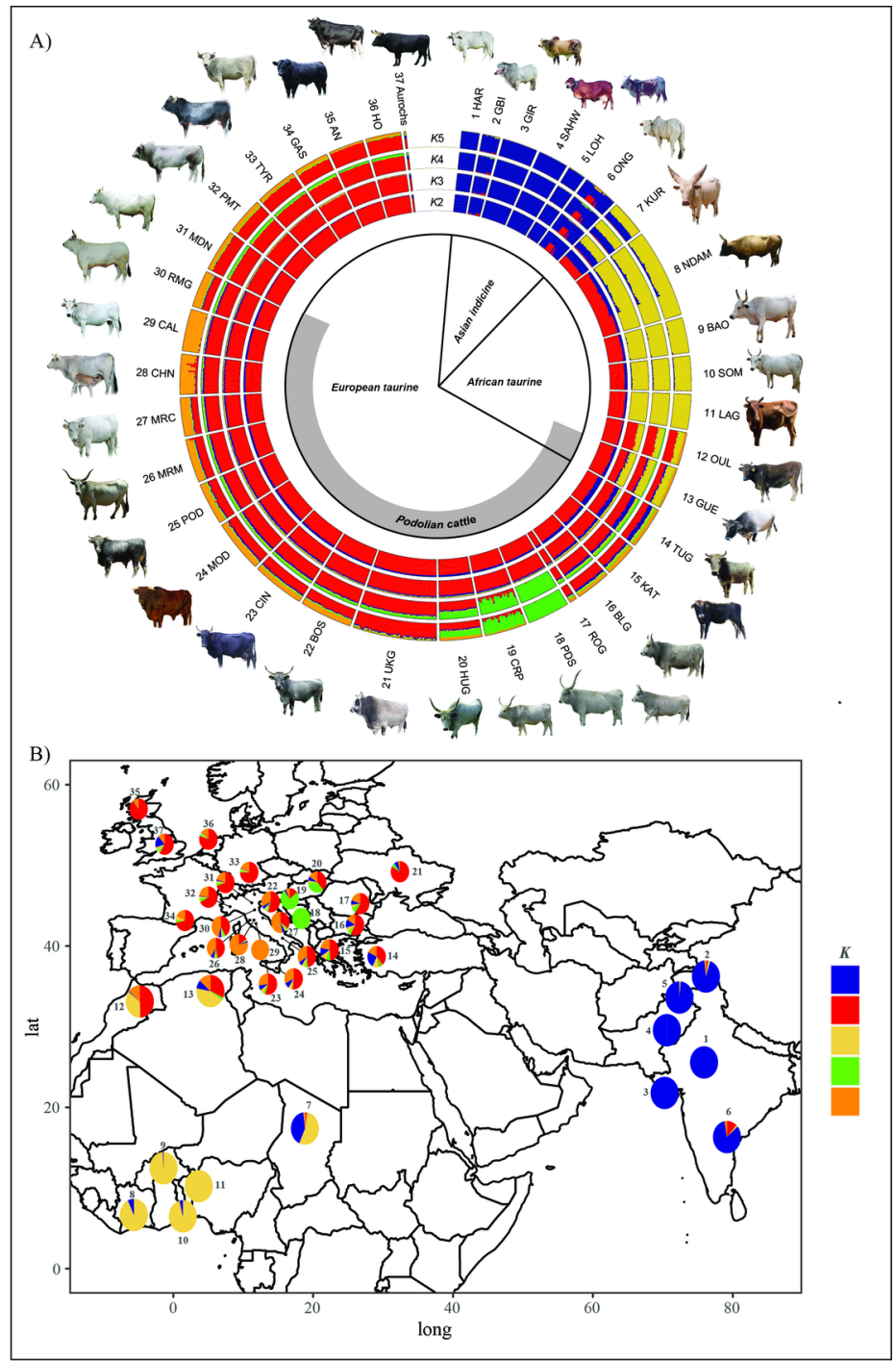




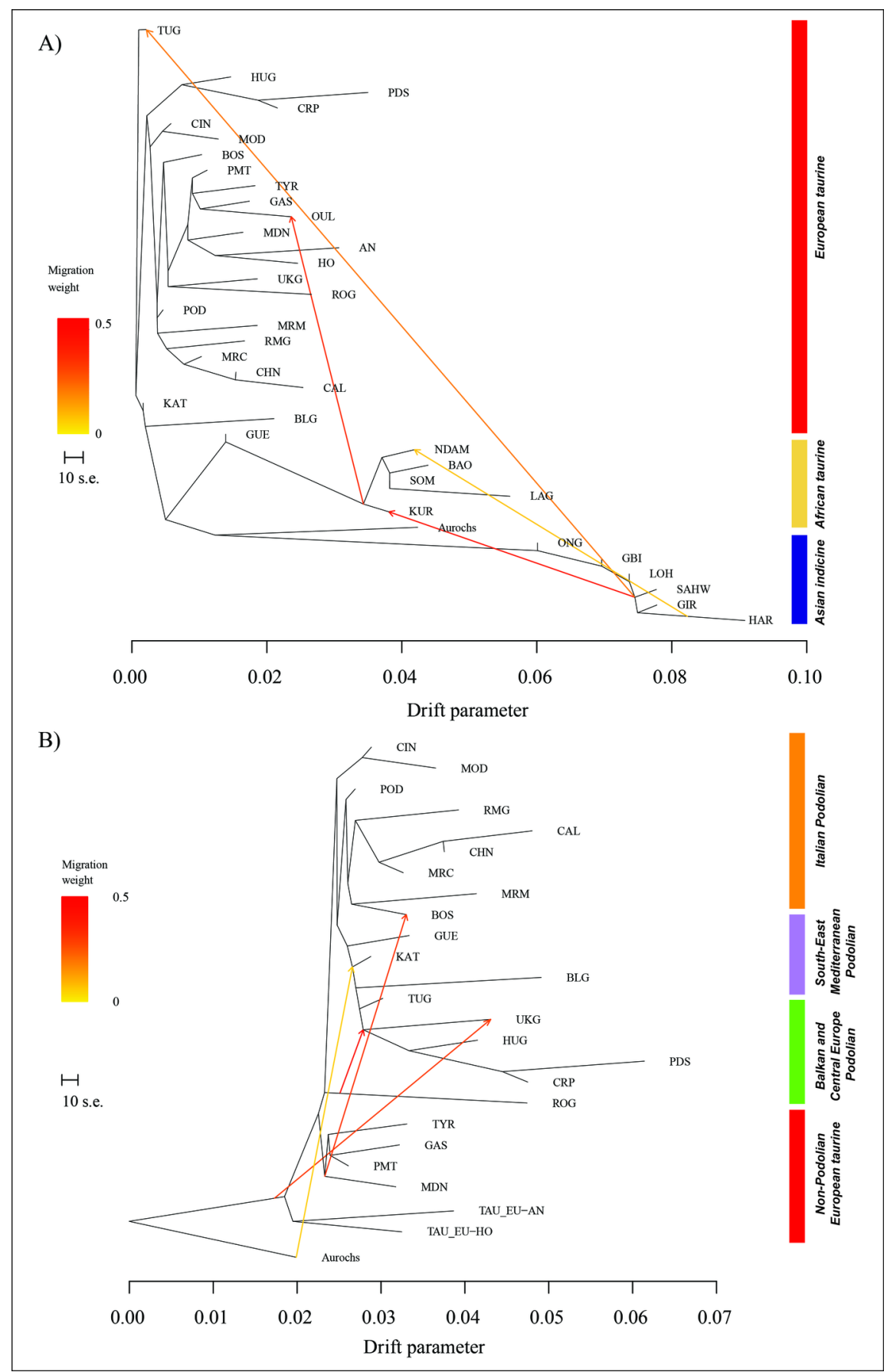



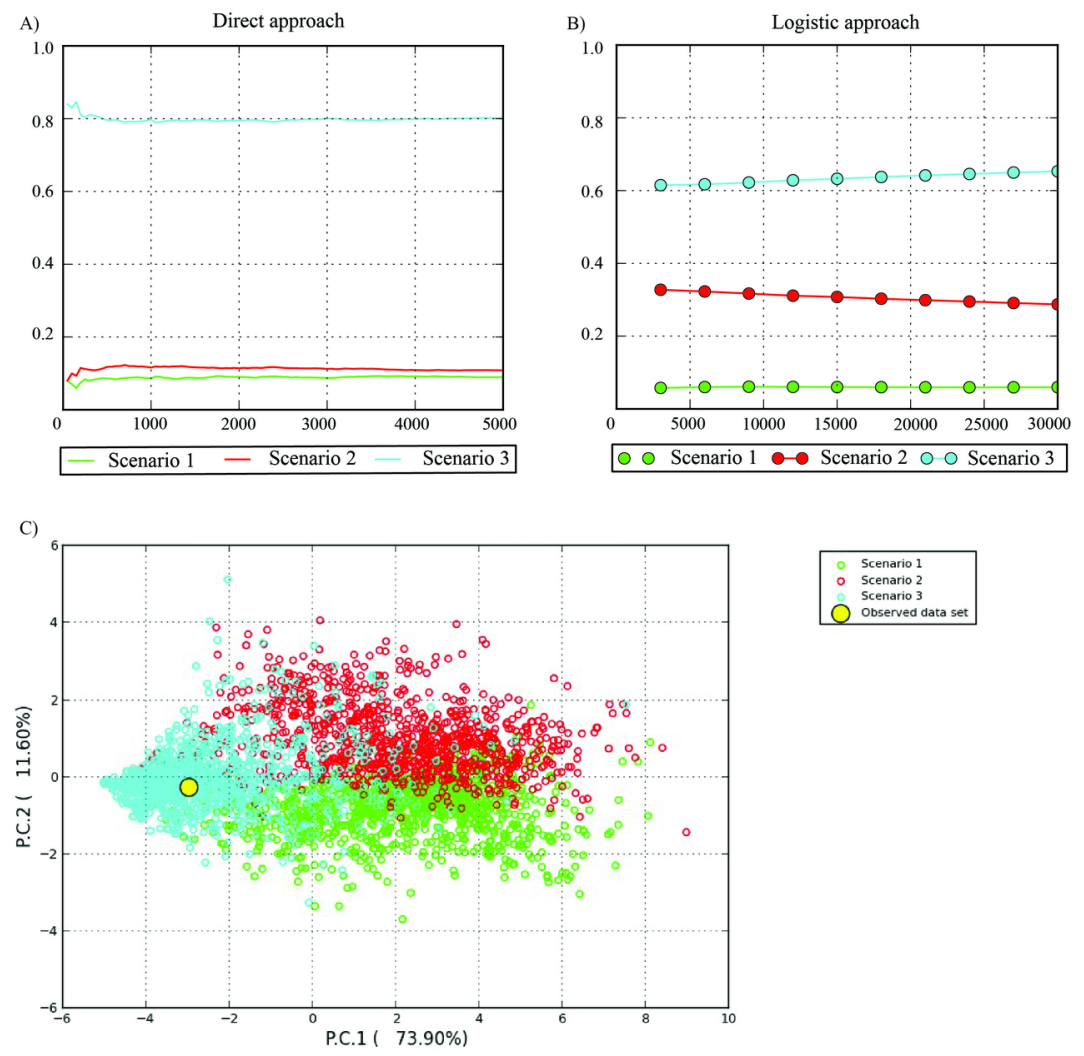

\begin{tabular}{ll}
\hline & Scenario 1 \\
0 & Scenario 2 \\
Scenario 3 &
\end{tabular}

O Observed data set 